\title{
Testing a Model for the Genetic Structure of Personality: A Comparison of the Personality Systems of Cloninger and Eysenck
}

\author{
A. C. Heath, C. R. Cloninger, and N. G. Martin
}

\begin{abstract}
Genetic analysis of data from 2.680 adult Auscralian twin pairs demonstrated signin̂cant genetic contributions to variation in scores on the Harm Avoidance. Noveity Seeking, and Reward Dependence scaies of Coninger's Tridimensional Personality Questionnaire (TPQ), accounting for between $54 \%$ and $61 \%$ of the stable variation in these traits. Multivariare generic triangular decomposition models were itted to determine the extent to which the TPQ assesses the same dimensions of heritable variation as the revised Eysenck Personality Questionnaire. These analyses demonstrated that the personality systems of Eysenck and Cloninger are not simply aiternative descriptions of the same dimensions of personality, but rather each provide incomplete descriptions of the structure of heritable personality differences.
\end{abstract}

Much research has been published on the factorial structure of personality, and many theories of personality structure have been propounded (e.g., Eysenck \& Eysenck, 1969, 1976; Gray, 1982; McCrae \& Costa, 1989; Tellegen. 1985). Much of this work has used samples of unrelated individuals. However, a growing body of data indicates an important contribution of genetic factors to personality differences (Eaves, Eysenck, \& Martin. 1989; Loehlin, 1992). Support for the role of genetic factors comes from studies using a variety of personality assessments, including studies of separated twins (Bouchard, Lykken, McGue, Segal. \& Tellegen. 1990; Pedersen, Plomin, McClearn, \& Friberg, 1988; Shields, 1962; Tellegen et al., 1988), of adoptees and their families (Loehlin. 1981; Loehlin, Willerman, \& Horn, 1985; Scarr, Webber, Weinberg, \& Wittig, 1981), of twin pairs reared together (Eaves et al., 1989; Rose \& Kaprio. 1988; Rose, Koskenvuo, Kaprio, Sarna, \& Langinvainio, 1988), and of twin pairs and their parents, siblings, and adult children (Eaves, Heath, Neale, Hewitt, \& Martin, 1993), and using ratings by informants (Heath, Neale, Kessier, Eaves, \& Kendler. 1993) as well as self-report data. Athough a genetic influence on personality has been demonstrated for a wide range of personality scaies, attempts to formulate a parsimonious model for

A. C. Hearh. Deparment of Psychiatry, Deparment of Psychology, and Department of Genetics. Washington University School of Medicine. C. R. Coninger. Department of Psychiatry and Deparment of Genetics. Washington University School of Medicine; N. G. Martin. Queensiand Institute of Medical Research. Brisbane, Queensland. tustralia.

Data collection was supported by Alcohol. Drug Abuse, and Mental Health Administration (ADAMHA) Grant AN07728 and by a grant irom the Auscralian National Heaith and Medical Research Council. Data analysis was also supported by ADAMHA Grants AA03539. tA07535. DA05588, MH31302. and MH40828.

We acknowledge the assistance of Sue Mason. Ann Eldridge. Olivia Zhang, and the late Ulich Kehren and the helprul comments or Gregory Carey and Kay Phillips.

Correspondence concerning this article should be addressed to $A$. C. Heath. Department of Psychiatry, Wasnington Universiry School of Medicine. 1940 Children's Place. St. Louis. Missouri 63110. the undertying genetic structure of personality have been much rarer than descriptions of the phenotypic structure. Because quite different genetic and environmental factor structures may underlie the observed phenotypic structure of personality (e.g., Heath \& Marin, 1990; Kendler. Heath, Martin, \& Eaves, 1987), performing separate genetic analyses of personality factors defined by phenotypic, that is, within-person, correlations may be quite misieading about the underlying genetic structure of personality (Heath \& Martin, 1990; Heath. Neale, Hewitt, Eaves, \& Fulker. 1989).

Cloninger $(1986,1987,1988,1991)$ has proposed a three-factor model for the structure of personality, which is hypothesized to have a close correspondence with the underlying genetic structure, and has developed a self-report questionnaire, the Tridimensional Personality Questionnaire (TPQ; Cloninger, Przybeck, \& Svrakic, 1991), to assess three postulated dimensions of personality: Harm Avoidance (HA), Novelty Seeking (NS), and Reward Dependence (RD). In this article, we use data from a mailed questionnaire survey of a large Australian twin sample to test whether scores on these personality dimensions are indeed substantially influenced by genetic factors. We also it genetic models to self-report responses to the revised Eysenck Personality Questionnaire (EPQ-R; Eysenck, Eysenck. \& Barrett. 1985) obtained from the same subjects in the same questionnaire. The Eysenckian personality dimensions have been extensively studied in genetic studies using twins and their family members (Eaves et al., 1989; Eaves et al., 1993), separated twin pairs (Pedersen et al., 1988), and adoptees (Scarr et al.. 1981) and thus provide a basis for comparing the results from this study with results of other behavioral genetic surveys using a variery of different research designs. We tit multivariate genetic models (Heath, Neale, et al., 1989; Martin \& Eaves. 1977; Neale \& Cardion. 1992) to determine the extent to which the TPQ assesses the same dimensions of genetic variation as the EPQ-R (Eysenck \& Eysenck. 1976; Eysenck et al.. 1985) and the extent to which it assesses new dimensions of genetic variability (ct. Martin. Eaves. \& Fulker. 1979). The methods that we use have broad appiicability in research aimed at simplifying our understanding of the structure of personality from an etiologic perspective. 
Method

\section{Sample}

Data for this report derive from the 1989 follow-up mailing of the Ausuralian National Heaith and Medical Research Council (NH\&MRC) volunteer adult twin panel. In 1980-1981, a 12-page questionnaire was mailed to 5.967 adult twin pairs aged 18-88 (Eaves et al.. 1989: Mariin \& Jardine. 1986). Completed questionnaires were retumed by both members from 3.808 twin pairs $(64 \%$ pairwise response rate) and by one twin only from 576 pairs $(69 \%$ individual response rate). In 1988-1989, twin pairs in which both twins had cooperated in the 1981 survey were mailed a follow-up questionnaire, with remailings and telephone follow-up of nonrespondents. Twins who did not return a mailed questionnaire were given the option of an abbreviated telephone interview. Mailed questionnaire or telephone interview data were obtained from both members of 2.997 twin pairs (79\% pairwise response rate. or $82 \%$ if we exclude from the target sample 139 twin pairs in which one or both twins were deceased by the time of the follow-up survey) and from one twin only from 334 pairs $(83 \%$ individual response rate). However, because it was not possible to obtain personality data by telephone interview, data for the present report are limited to those twins who returned questionnaires. Final sample sizes are reported in Table 1. These figures correct previous reports on the 1981 sample (Eaves et al., 1989; Martin \& Jardine, 1986): At follow-up, it was discovered that 2 twin pairs had been doubly ascertained. and hence counted twice, in the 1981 survey and that sex had been miscoded for 3 few additional twins.

As has generaily been found in volunteer twin panels (Eaves et al.. 1989; Lykken, McGue. \& Tellegen. 1987; Lykken, Tellegen. \& DeRubies, 1978), there was an excess of femaie same-sex pairs, and of monozygotic (MZ) pairs. in the original Australian NH\&MRC twin panel, and this was reflected in the total number of pairs in the target sample to whom questionnaires were mailed in the follow-up survey. A similar partern was seen in the proportions of pairs in which both twins returned questionnaires in the follow-up survey, with completion rates highest in $M Z$ female pairs ( $76.8 \%$ pairwise response rate), intermediate in $M Z$ maie and dizygotic (DZ) female pairs $(70.7 \%$ and $72.4 \%$, respectively), and lowest in DZ male and opposite-sex twin pairs $(63.7 \%$ and $62.4 \%$ respective pairwise response rates). The sample consisted of adults (minimum age 18) when initially assessed in 1981 so that at follow-up the twin pairs were older than in many twin studies (average age 41.58 years, range 25-89), with relatively few twins still living together with their cotwin (4\%). Any transient effects of living together in the same environment (e.g., Rose \& Kaprio, 1988) would be expected to be minimal in this group.
To assess the short-term test-retest reliability of the assessment insiruments used in the 1989 questionnaire, a repeat questionnaire was mailed to 500 female twins and 500 male twins. with completed questionnaires retumed by 451 female and $\$ 30$ male respondents. Because the retest questionnaire was mailed before the last questionnaires had been returned in the 1989 survey, and was only mailed to twins who had already retumed the 1989 questionnaire, uncooperative individuals are undersampled in the retest sample. The average test-retest interval for respondents was 2.1 years.

\section{Measures}

Included in the 1989 questionnaire were a short-form 54 -item version of the Tridimensional Personality Questionnaire (TPQ; Coninger et al. 1991) and the short-form 48-item revised Eysenck Personality Questionnaire (EPQ-R: Eysenck et ai., 1985). The TPQ was designed to assess the three higher order personality dimensions detined by Cloningex's (1987) unified biosocial theory of personality: HA. NS, and RD. In the short-form TPQ used in the present-study, 18-item scales were used to assess each dimension. Scores on eactī of these dimensions were derived as the proportion of responses made by the respondent in the direction predicted for bigh HA, high NS, or high RD responders. Data from the reliability subsample were used to test for heteroscedasticity for each scale: Linear, quadratic, and cubic terms were estimated for the polynomiai regression of the squared interoccasion difference score on the average score across the two occasions, that is, the regression of ( $\mathbf{s l}$ $-s 2)^{2}$ on $(s 1+s 2) / 2$, where $s 1$ and $s 2$ denote scores on first and second occasions. Polynomial regressions were modest, yielding squared muitiple correlations in the range of $2.18 \%-2.72 \%$ for women and $2.45 \%-6.32 \%$ for men, and these values were not reduced by standard square-root, logarithmic, or arcsine transformations of the raw scores. Because the raw scores did not exhibit excessive heteroscedasticity, no data transformation was considered necessary. Internal consistency (Cionbach's alpha) and test-retest reliability coefifients were computed separately for the following birth cohorts: 1956-1964, 19461955, 1931-1945, and pre-1931. Internal consistencies for the full 1989 sample for women were $0.83-0.85$ for HA. $0.66-0.72$ for NS, and 0.59 0.62 for $R D$; for men, they were $0.78-0.35$ for HA, $0.68-0.73$ for NS, and $0.58-0.68$ for $R D$, acceptably high values and comparable with those reported for the full TPQ scales (Coninger et al., 1991). For the reliability subsample. test-retest correlations for women were 0.76 0.84 for HA. $0.70-0.82$ for NS, and $0.59-0.76$ for RD; for men, they were $0.73-0.83$ for HA, $0.58-0.30$ for NS, $(0.68-0.8$ if we exciude men born between 1931-1945, for whom test-retest reliability for this scale was much lower than for other age cohorts), and $0.62-0.71$ for $R D$,

Table !

Number of Twin Pairs Providing Personality Data in the 1989 Survey

\begin{tabular}{lcccc}
\hline Zygosity group & Both twins & One twin & Neither twin & $\begin{array}{c}\text { Total } \\
\text { pairs in } \\
\text { target } \\
\text { sample }\end{array}$ \\
\hline MZ female pairs & 946 & 104 & 182 & 1.232 \\
MZ maie pairs & 401 & 75 & 91 & 567 \\
DZ female pairs & 541 & 100 & 106 & 747 \\
DZ maie pairs & 223 & 72 & 55 & 350 \\
DZ opposite-sex pairs & 569 & 192 & 151 & 912 \\
Total & 2.680 & 543 & 585 & 3.808 \\
Total (\%) & 70.4 & 14.3 & 15.3 & \\
\hline
\end{tabular}

Note. $\mathrm{MZ}=$ monozygotic: $\mathrm{DZ}=$ dizygotic. 
Indicating good short-term stability of these variables. These reliability soefficients were a little smaller than 6-month tert-retest reliability coeficients reported for a U.S. national probabiiity sample (Cloninger et ai.. 1991), which was to be expecred because we used shorer scales and a longer 2-year follow-up interval. No sex difference was observed for VS (mean scores of 0.4 for women and 0.41 for men). but women scored nigier than men on both HA (0.44 vs. 0.33$)$ and $R D(0.64$ vs. 0.55$)$; these findings are consistent with U.S. normative data for Whites (Cioainger et al.. . 1991).

The short-form EPQ-R (Eysenck et al.. 1985) assesses the Eysenckian personality dimensions of Extraversion (E); Neuroticism (N); Social Conformity, or Lie (L) and Toughmindedness, or Psychoticism (P) (Eysenck \& Eysenck, 1985). The $E$ and $N$ items and most $L$ items are a subset of the items of the original EPQ (Eysenck \& Eysenck, 1975), but the $P$ scale has changed markedly from the EPQ (Eysenck \& Eysenck. 1976: Eysenck et al., 1985). Raw scores were computed in the same manner as for the TPQ. Tests for heteroscedasticity using the reliability subsample indicated modest heteroscedasticity for $E$. $N$, and $L\left(R^{2}=\right.$ $3.97 \%-6.52 \%$ for women and 3.82\%-7.92\% for men), which was nor reducedby standard data transformations. Heteroscedasticity for $P$ was more pronounced $\left(R^{2}=13.3 \%\right.$ for women and $9.75 \%$ for men), probabiy reflecting the very low endorsement frequencies of the items of the $P$ seale, even in its revised version. but again was not reduced by standard data transformations. Internal consistency coefficients for the full 1989 sample for women were $0.85-0.87$ for E. $0.81-0.84$ for $N, 0.70$ 0.74 for $L$, and $0.31-0.44$ for $P$; for men, they were $0.85-0.87$ for $E$, $0.82-0.83$ for $N, 0.71-0.78$ for $L$, and $0.36-0.46$ for $P$. Corresponding test-retest reliability coefficients for the reliability subsample for women were $0.75-0.86$ for $E, 0.72-0.86$ for $N, 0.69-0.83$ for $L$. and $0.57-0.71$ for $P$ (with test-retest correlations for $P$ in the range of 0.62 0.71 for those born after 1930 ); for men, they were $0.83-0.87$ for $E$. $0.76-0.82$ for $N, 0.72-0.81$ for $L$ and $0.41-0.72$ for $P$ (again with testretest correlations for $P$ falling in the more acceptable range of 0.61 0.72 , for those born after 1930). We note that the revised $P$ seale performs pooriy in this general population sample. having low internal consistency and low test-retest reliability, particulariy in older respondents. Mean scores of female respondents were higher than for male respondents for $N(0.41$ vs. 0.32$)$ and $L(0.54$ vs. 0.47$)$; no sex difference was observed for $E$ ( 0.57 in both sexes), and men obtained higher scores for $P(0.13$ for women vs. 0.19 for men $)$.

\section{Representativeness of Sample}

Estimates of genetic and environmental parameters from twin data can be seriously biased if sampling is nonrandom with respect to the traits under study (e.g., Lykken, McGue, \& Tellegen, 1987: Marin \& Wilson. 1982; Neale. Eaves. Kendler. \& Hewith 1989). In the present sudy, the original twin panel was a volunteer panel. and the only twin pairs included in the 1989 mailing were those pairs in which both twins had responded to the original 1981 survey. Thus. nonrepresentative sampling could arise because (a) the distribution of personality scores for twins who volunteered for the NH\&MRC twin panel was unrepresentative of personality scores for the general population. (b) there was an association between personality and nonresponse to the 1981 questionnaire mailing, or (c) there was an association berween personality and nonresponse to the 1989 questionnaire mailing

There are no Australian norms for the TPQ or EPQ-R with which our data can be compared. but normative data were available for the 1981 survey using the EPQ and did not indicate any deviation from random sampiing with respect to personality traits in the original survey (Martin \& Jardine. !986). In contrast with studies of sampies of unrelated individuals. data on twin pairs can provide important information about representativeness of sampling ie.g. Heath. Neale. et al.. 1989: Neale \& Cardon. 1992). even where no normative population data are available. Most plausible forms of nonrandom sampling will lead to differences in mean and variance of personality scores between $M Z$ and $D Z$ pairs, differences that are not predicted under most genetic modeis (Heath. Neale, et al.. 1989; Neale \& Cardion, 1992). In testing for such differences. we ignored the nonindependence of observations from members of a twin pair. Our tests are therefore conservative, tending to find significant differences when none are present. In female respondents from same-sex pairs. no zygosity differences in mean or variance were found for any of the TPQ or EPQ-R scales. In male same-sex pairs. $M Z$ twins obtained lower NS scores ( 0.39 vs. 0.43 for $D Z$ twins), $t(1384)$ $=3.94, p<.001$; lower $\mathrm{P}$ scores $(0.18$ vs. 0.20). $2(1392)=2.72, p<.001$ and higher $L$ scores $(0.49$ vs. 0.46$), t(1390)=2.51, p=.01$; however no significant differences in variance were found. Female twins from opposite-sex pairs had lower $\mathrm{L}$ scores than female same-sex twins $(0.52$ vs. 0.55$),(3855)=3.50, p<.001$, but did not differ on any of the other scales. Male twins who were reared with a femaie cotwin had significantly higher scores on both HA $(0.36$ vs. 0.32$), t(2024)=3.66, p<$ .001 , and $N(0.35$ vs. 0.31$), .(2027)=3.69, p<.001$, and a slightly lower L score $(0.45$ vs. 0.48$), t(2026)=2.04, p<.04$.

A more direct check on the representativeness of our sample was provided by the comparison of twins whose cotwin did not cooperate in the study with twins from pairs concordant for study participation. If personality differences on a given dimension are associated with differences in cooperativeness, we would expect to observe significantly higher (or lower) scores on that dimension of the twins from the pairs discordant for cooperation (Heath. Neale, et al., 1989; Neale \& Cardon, 1992). In the 1989 data. no significant mean differences were found for either TPQ or EPQ-R scores in women, and in men a significant difference was found only for the EPQ-R P scale $(M=0.19$ in twins from concordant cooperative pairs and $M=0.21$ in twins with uncooperative cotwins). This difference was only of marginal significance, $t(2029)=$ $2.00, p=.05$, but in the expected direction, with twins with uncooperative cotwins being more Toughminded. There was also an elevated variance in $\mathrm{N}$ scores in male twins from discordant pairs $\left(s^{2}=0.30\right)$ compared with twins from concordant cooperarive pairs $\left(s^{2}=0.26\right)$, $F(1911,116)=1.31, p=.04$, raising the possibility that extremely stabie men and extremely unstable men were underrepresented in the sample: however, this difference was again of marginal significance. No other variance differences were found for any other scale for men, nor were any variance differences found for women.

These sampling checks indicate that we may have good confidence in the representativeness of our sample of female twins. The most direct test comparing twins from pairs concordant versus discordant for study participation, suggests that the male twins are representative of the general popuiation for all scales except the $P$ scale, and here the mean difference is probably too slight to lead to a substantial bias in estimates of genetic and environmental parameters. However the significant zygosity differences in mean for the male twins from like-sex and oppositesex pairs indicates the possibility of nonrepresentative sampling or other processes not captured by our simple genetic models. These mean differences were small. however.

\section{Data Summary}

Because members of a twin pair share the same age, age effects will inflate the corretations between $M Z$ and between $D Z$ twin pairs equally and thus will mimic the effects of shared environment (Eaves et al., 1989). To test for such effects. linear, quadratic. and cubic terms of the poiynomial regression of respondents' scores on age were computed for each scale. separateiy for each sex. With the exception of NS. L, and. in men oniy, $P$. all regressions were either nonsignificant or yielded squared muitiple correlations of less than 2\%. values too small to bias estimates of genetic and environmental parameters. Age regressions for NS. L. and $P$ were highiy signinicant. with squared multiple correiations in the 
range of $+.0 \%-3.3 \%$. and so for these scales we used age-corrected scores (i.e.. residual scores from the polynomial regression on age).

For univariate genetic analyses of each personality scale. $2 \times 2$ covariance matrices were computed for each zygosity group, giving the variance and covariance of first and second twins from pairs with complete data for that scale. Twins were assigned as first or second twins randomly in the case of same-sex pairs. but opposite-sex pairs were reordered so that the first twin was always the fernale twin (Heath. Neale. et al.. 1989). For multivariate genetic analyses. $14 \times 14$ covariance matrices were computed for each zygosity group, giving the variances and covariances of the scores of first and second twins on the three TPQ and four EPQ$R$ scales, using listwise deletion of missing data.

\section{Univariate Genetic Analyses}

Univariate genetic models were firted to twin pair covariance matrices by the method of maximum likelihood using LISREL 7.20 (Jöreskog \& Sörbom. 1988; Heath. Neale, et al., 1989: Neale \& Cardon. 1992: Neale. Heath. Hewith Eaves, \& Fulker 1989). In brief, following bionetrical genetic theory (e.g., Bulmer. 1980; Fisher, 1918: Mather \& Jinks. 1971), we can decompose the observed variance in a trait into proportions due to the additive effects of multiple genetic loci $(A)$, to nonadditive genetic effects (generic dominance or epistatic. i.e. multiplicative, interactions between loci; D), to shared environmental effects (C), and to within-family environmental effects (E), which make even an identical twin differ from his or her cotwin. In terms of structural equations, we have

$$
P_{i}=e E_{i}+c C_{i}+h A_{i}+d D_{i},
$$

and

$$
V P=e^{2}+c^{2}+b^{2}+d^{2},
$$

where $P_{i}$ is the phenotype (e.g., personality score, sealed as a deviation from zero) of the $i$ th twin $(i=1,2)$, and genetic and environmental deviations $A, D . C$, and $E$ are assumed to be standardized with zero mean and unit variance: VP is the phenotypic variance. Path coefficients e, c. h, and $d$ were constrained to be equal in first and second twins, and in $M Z$ and $D Z$ twins of the same sex. but in some models we did allow values of these parameters to vary as a function of sex. From biometric genetic theory, the covariances of the additive genetic deviations $\left(A_{i}\right)$ and nonadditive generic deviations $\left(D_{i}\right)$ will be unity in $M Z$ twin pairs and. assuming random mating for personality traits (i.e., no tendency tor the genetic deviations of spouse pairs to be correlated with respect to personality traits), will be 0.5 and 0.25 , respectively, in DZ twin pairs. The covariance of additive and dominance effects $A_{i}$ and $D_{i}$, both within individuals and between pairs, will be zero. By detinition, the covariance of shared environmental effects $\left(C_{i}\right)$ will be unity, and that of within-family environmental effects $\left(E_{i}\right)$ zero, in both $M Z$ and $D Z$ pairs. Thus, our model implies the assumption that the environments of $M Z$ pairs are no more highly correlated than the environments of $D Z$ pairs. ar least as far as concerns those environmental influences that determine personality variation in the age group and popuiation under study (Heath. Neale. et al. 1989). In cross-sectional data, withinfamily environmental effects will include measurement error effects that are uncorrelated berween members of a twin pair. Shared and within-family environmental effects are assumed to be mutually uncorreiated and to be uncorrelated with either additive or nonadditive genetic effects. This latter assumption implies no genotype-environment correlation (Eaves. Last Martin, \& Jinks. 1977; Plomin. Defries. \& Loehlin. 1977), for example. no tendency for individuais with a genetic predisposition to high $\mathrm{HA}$ to be especially likely to experience anxiogenic (i.e.. HA inducing) environments. For those personality traits that have been extensively studied. $E$ and $V$, the assumptions of random mating and no genotype-environment correlation appear to be weil suppored by the data trom twin tamily studies and adoption studies (Eaves et al.. 1989: Eaves et al.. 1993: Scarr et al.. 1981), and we anticipate that this will also prove to be the case for the personality dimensions of the TPQ.

In model firting, we compared the it of three basic models: a nongeneric model (e. c), an additive generic model (e, h), and a full generic model allowing for both additive and nonadditive genetic efiects (e. $h$. d). These three modeis assumed no heterogeneity of parameters as a function of sex. In addition. each model was elaborated by allowing for (a) an overail sex difference in variance. estimaning sex-dependent parameters with the constraint $e_{m}=k e_{f}, c_{m}=k c_{f}, h_{m}=k h_{r}$ and $d_{m}=$ $k d_{f}$, where $k^{2}$ gives the ratio of the phenotypic variance in men to that in women; (b) estimating separate genetic and environmental parameters for each sex (implying a Genotype $\times$ Sex interaction), or (c) allowing aiso either the covariance of additive genetic effects in opposite-sex pairs $\left(r_{G}\right)$ or the covariance of shared environmental effects ( $\left.r_{C}\right)$ to be istimated as a free parameter (Eaves. 1977; Heath. Neale. er al., 1989; Neale \& Cardon. 1992). Model $c$ allows for the possibility that, in addition to sex differences in the magnitude of genetic and environmental effects, some gene effects, or some shared environmental effects, are sex specific. We did not attempt to fit a model that constrained all generic effects to be nonadditive because this would have no sensible biological interpretarion (Mather \& Jinks. 1971). In data on twin pairs reared together, if there is generic variation, the effects of genetic nonadditivity and shared environment are confounded. the former tending to produce $D Z$ twin correlations !ess than one half the $M Z$ correlations and the latter to inflate the $D Z$ correlation to be greater than one balf the $M Z$ correlation (Martin. Eaves, Kearsey, \& Davies, 1978). Thus, we could not include both shared environmental effects and nonadditive genetic effects in the same model. However the absence of evidence for shared environmental influences on personality variation from separated twin and adoption studies (Bouchard et al., 1990; Loehlin et al., 1985; Pedersen et al., 1988; Tellegen et al., 1988; Scarr er al., 1981) suggests that this confounding will not be an important problem.

Models were fitted to twin pair covariance matrices by the method of maximum likelihood, using LISREI (Jöreskog \& Sörbom, 1988). The goodness of fit of models was compared by chi-square test, and nested modeis were compared by likelihood ratio chi-square test (Neale \& Cardon, 1992: Neale, Hearh, et al., 1989). Parameter estimates under the best-âtting model or mode's for each personality trait are reported in standardized form. restandardizing the total expected variance in each sex to unity, for example, in the case of male parameters, as $\mathrm{h}_{\mathrm{m}}^{\prime}=\left(\mathrm{h}^{2}{ }_{\mathrm{m}}\right)$ $\left.\mathrm{VP}_{\mathrm{m}}\right)^{0.5}$, etc., where $\mathrm{VP}_{\mathrm{m}}=\mathrm{e}_{\mathrm{m}}^{2}-\mathrm{c}_{\mathrm{m}}+\mathrm{h}_{\mathrm{m}}^{2}+\mathrm{d}^{2}$. In some cases we report the proportion of stable variation accounted for by additive and nonadditive generic factors $\left(\mathrm{h}^{\prime 2}+\mathrm{d}^{\prime 2}\right) /(1-R)$, where $R$ is the test-retest reliability coeficient for a scale, estimated separately for each sex.

\section{Multivariate Genetic Triangular Decomposition}

Although univariate genetic analysis provides estimates of the contributions of additive and nonadditive genetic and within-family environmental effects to variation in each of our personality constructs. it teils us nothing about the extent to which different measures of personality are assessing the same dimensions of genetic or environmental variation. The recent proliferation of personality instruments in genetic studies (e.g., Bouchard et al.. 1990; Pedersen et 31., 1991; Tellegen et al., 1988) bas not been accompanied by an attempt to determine whether these instruments assess new dimensions of genetic variabiiity. Merely examining within-person correlations between personality traits may tell us little about this question: the observed "phenotypic" structure of personality may be quite different from the underlying genetic and environmental structures (Cloninger. 1987; Heath \& Martin. 1990). Instead. we have used methods of multivariate genetic analysis (e.g., Heath. Neale. et ai.. 1989: Marin \& Eaves. 1977; Neale \& Cardon. 
1992) to address this question. Whereas a conventional univariate genetic analysis utilizes only correlations between relatives within traits. and a conventional factor anaiysis only correlations within persons between traits. in a multivariate genetic analysis the additional information contained in the cross-correiations between relatives for different traits allows us to determine the extent to which genetic influences are shared in common by several traits. or are trait specific.

The inheritance of the Eysenckian personality dimensions of $E . N$. and $L$ has been extensively investigated (e.g. Eaves et al. 1989: Eaves et al. 1993; Heath, Eaves, \& Martin, 1989; Heath, Jardine, \& Martin. 1989; Heath \& Marin. 1990; Heath, Jardine, Eaves, \& Martin. 1988; Pedersen et al.. 1988: Rose et al.. 1988; Scart et al., 1981). Although the selection of items that define operationally the $P$ construct has changed markedly over time (e.g., Eysenck \& Eysenck, 1975, 1976: Eysenck et al. 1985), twin studies of versions of the $P$ seale prior to the EPQ- $R$ have aiso confirmed significant genetic influence for $P$ (Eaves \& Eysenck. 1977; Eaves et al., 1989). (However, the precise interpretation of the dimensions of genetic variability underlying responses to the $P$ scale remains a matter of some dispute; Heath \& Martin, 1990). In the present paper therefore. we wished to consider not only the heritability of the peitsonality constructs of the TPQ, but also the extent to which these constructs are assessing new dimensions of genetic variability (cf. Martin, Eaves, \& Fulker, 1979). To address these questions, we have fitted triangular decomposition genetic models (Neale \& Cardon, 1992) to the $14 \times 14$ twin pair covariance matrices for the EPQ-R and TPQ personality dimensions. As in the univariate genetic analyses, models were fitted to the covariance matrices for the five zygosity groups, allowing for sex-dependent parameters.

Under the most general triangular decomposition model, with seven personality variables, we would estimate seven sets of orthogonal additive genetic factors $\left(A_{1} \cdots A_{7}\right)$, dominance generic factors $\left(D_{1}\right.$ etc.), shared environmental factors $\left(C_{1}\right.$ etc.), and within-family environmental factors $\left(E_{1}\right.$ etc.). Variances and covariances of latent genetic and environmental factors berween twin pairs will be the same as in the univariate genetic case. Our structural equations now will be

$$
\begin{aligned}
P_{1 i}=e_{11} E_{1}+c_{11} C_{1}+h_{11} A_{1}+d_{11} D_{1}, & \\
P_{2 i}=e_{21} E_{1}+c_{21} C_{1}+h_{21} A_{1}+d_{21} D_{1} & +e_{22} E_{2}+c_{22} C_{2}+h_{22} A_{2}+d_{21} D_{2}, \\
P_{3 i}=e_{31} E_{1}+c_{31} C_{1}+h_{31} A_{1}+d_{31} D_{1} & +e_{32} E_{2}+c_{32} C_{2}+h_{32} A_{2}+d_{31} D_{2} \\
& +e_{33} E_{3}+c_{33} C_{3}+h_{33} A_{3}+d_{33} D_{3},
\end{aligned}
$$

and so on. Here $P_{1 i}$ denotes the first personality variable of Twin $i$ ( $i=1$ or 2$), P_{2 i}$ denotes the second personality variable, and so on. with the first within-family environmental. first shared environmental, first additive genetic, and first nonadditive genetic factors allowed to have nonzero loadings on all seven personality variables; the second set of factors having nonzero loadings on all except the first personality variable: the third set of factors having nonzero loadings on all except the first two personality variables and so on. Thus. our matrices of factor loadings will be triangular in form. In the most general model. matrices of genetic and environmental loadings are unconstrained: that is. there is no requirement that the pattern of genetic factor loadings should mirror the pattern of environmental factor loadings, nor indeed that the pattern of nonadditive genetic loadings should be the same as the pattern of additive genetic loadings. In some analyses, however, we constrained nonadditive genetic loadings on some factors to be a multiple of corresponding additive generic loadings on that factor (i.e.. $\mathrm{d}_{\mathrm{i}, \mathrm{l}}=\mathrm{k}_{1} \mathrm{~h}_{\mathrm{i}, 1}, i=$ $1.7 ; d_{j, 2}=k_{2} h_{j, 2}, j=2 . \cdots 7$, and so on). that is, constrained the patrem of additive and nonadditive genetic loadings on a factor to be similar. As in univariate genetic analyses, genetic and environmental factor loadings were constrained to be equal in first and second twins. and in $M Z$ and $\mathrm{DZ}$ twins. but were allowed to differ between sexes.

When a full seven-factor model is fitred. and all parameters of the model are identined. the ordering of the personality variabies will be arbitrary: with different orderings giving the same goodness of fit by chisquare test: but in submodeis estimating fewer than seven factors for one or more sources oi variability (i.e.. counting within-family environmental effects, additive genetic effects. nonadditive genetic effects. and shared environmental effects each as one source of variability) this will no longer be the case. Furthermore. as in the univariate genetic case. with data on only twin pairs reared together, we cannot estimate simultaneousiy seven nonadditive genetic and seven shared environmental factors: as a consequence of this, seven-factor solutions with different orderings of personality variables will not necessarily give identical fits to the dara. Likewnse. as a consequence of the inclusion of opposite-sex twin pairs in these analyses, sex differences in generic or environmental factor loadings may lead to different fits for seven-factor solutions with different orderings of variables (K. Phillips. 1993, personal communication). Because we were interested in determining the extent to which the TPQ assesses new dimensions of genetic (or environmental) variability, we ordered the personality variables so that the EPQ-R traits (E, $N, L$, and $P$ ) preceded the IPQ traits (HA. NS, and RD). Thus, our first additive genetic factor would assess the extent to which additive genetic influences on $\mathrm{E}$ aiso affected responses to the remaining six personality variables; the second generic factor would assess how much additive genetic influences on $\mathrm{N}$ aiso determined responses to the remaining five personality variables, after allowing for the first dimension of genetic variability associated with $E$, and so on, with similar interpretations for the nonadditive generic and within-family environmental factors. We describe this analysis as predicting scales of the TPQ from scales (or genetic and environmental factors) of the EPQ-R. For each of the TPQ scales, the sum of the squared loadings on genetic or Environmental Factors $1-4$ gives the total genetic variance (or environmental variance) in the seale that is accounted for by genetic factors (or by environmental factors) that aiso influence the EPQ-R scales, and the sum of the squared loadings on the remaining factors gives the residual genetic or environmental variance for the scale that is not accounted for by the EPQ-R We aiso repeated the analysis reordering the data so that the $T P Q$ seales prececied the EPQ-R scaies to determine the proportion of the total genetic or environmental variance in each EPQ scale that was accounted for by genetic or environmental factors assessed by the TPQ (i.e., predicting the scales of the EPQ-R from the seales of the TPQ). We note that in cross-sectional data as in the univariate genetic case, the withinfamily environmental loadings $E_{11}$ and so forth will also be inflated by measurement error effects. In contrast with the conventional common factor and genetic factor modeis (e.g., Heath, Neale. et al., 1989; Martin \& Eaves. 1977; Neale \& Cardon. 1992), the full seven-factor triangular decomposition model does not distinguish between common factor and specinfc factor variance and does not estimate specific factor effects for any variable except the final (seventh) personality variable. In this regard firting a multivariate generic triangular decomposition model is more ciosely related to principal-components analysis (Morrison. 1976) than to factor anaiysis. We therefore adjusted our estimate of the residual within-family environmental variance for a scale by subtracting an estimate of the error variance for that scale, obtained as $(1-R)$, where $R$ is the test-retest correlation for that scale.

In addition to assessing the parameter estimates and goodness-of-fit chi-square under the full unconstrained seven-factor trianguiar decomposition model. we aiso fitted submodels in which loadings on the first three nonadditive genetic factors (predicting the EPQ-R from the TPQ) or first two or four factors (predicting the TPQ from the EPQ-R) were constrained to be multiples of the loadings on the corresponding additive genetic factors. No constraints were imposed on additive and nonadditive genetic loadings on the remaining four (or three) residual factors. This is the pattern of genetic loadings that we would expect if there are heritable dimensions of personality influenced by both additive and nonadditive genetic effects and closely related to the dimensions of the 
personality system of Cloninger (or Eysenck) that. together with other heritable dimensions. intluence responses to the EPQ-R (or TPQ). Finally, nonsignificant loadings on the residual factors were also dropped to further simplify the model. In analyses predicting the TPQ from the $E P Q-R$. we examined the improvement in fit when nonadditive genetic loadings on Factors 3 and 4 (corresponding to the $L$ and $P$ scales) were ixed to zero. and shared environmental factors were estimated instead. In analyses predicting the EPQ-R from the $T P Q$, shared environmental effects (rather than nonadditive genetic effects) were likewise estimated for Factors 6 and 7. Estimates of genetic and environmental variances explained by genetic and environmental factors of the TPQ (or EPQ$R$ ), and residual genetic and environmental variances. are reported under the simplified model, where nonadditive genetic factor loadings on Factors $1-3$ (or $1-4$ ) were constrained and nonsigninicant parameters were removed from the model but were extremely close to those obtained under the full seven-factor decomposition.

\section{Results}

\section{Univariate Genetic Analyses}

Table 2 summarizes twin pair correlations for each scale of the TPQ and EPQ-R. MZ correlations were higher than the corresponding same-sex $D Z$ correlations for all scales, consistent with a genetic influence on each personality dimension. For all three TPQ scales, as well as for $E$ and $N, D Z$ correlations were less than half the corresponding $M Z$ correlations, suggesting either an absence of shared environmental influences or that any shared environmental influences were masked by genetic nonadditivity (i.e., genetic dominance or epistasis). For $L$ and $P$, however, same-sex DZ correlations were consistent with a modest shared environmental influence (i.e., greater than half the corresponding $\mathrm{MZ}$ correlations).

Table 3 summarizes the results of fitting univariate genetic models to twin pair covariance matrices. For all variables except $L$, all nongenetic models were rejected by chi-square test of goodness of fit. In the case of $L$, the full nongenetic model (Model 8) still gave a significantly worse fit than the most general model (Model 12) and so could be rejected by likelihood-ratio chi-square test. $\chi^{2}(2)=13.98, p<.001$. Thus, for each of the $T P Q$ and $E P Q-R$ personality dimensions we found signinicant evidence for genetic influences.
For HA and NS. modeis allowing for both nonadditive and additive genetic effects (Modeis 9-12) gave a signinicant improvement in fit. by likelihood-ratio chi-square test. compared with purely additive genetic models (Models $1-4)$. For each trait, there was a significant sex difference in variance (Mode! 10 gave a significantly berter fit than Model 9). For HA only, allowing for a Genotype $\times$ Sex interaction gave a substantial but nonsignificant improvement in fit. $x^{2}(2)=4.44, p=.11$. For $R D$. the simplest models to fit the data were Model 4, a purely additive genetic model allowing for a Genotype $\times$ Sex interaction, with the correlation between gene effects in the two sexes estimated as a free parameter $\left(r_{G}<1\right)$, and Model 10 , allowing for additive and nonadditive gene action with sex differences in variance. We could not choose between these two models by likelihood-ratio criteria. because neither model gave a significantly worse tit than the most general model (Model 12). However. the very low opposite-sex twin pair correlation for $R D$ leads us to suspect that with larger sample sizes it would be possible to confirm important Genotypé $\times$ Sex interaction for $R D$.

For both $E$ and $N$ the data were consistent with additive pius nonadditive genetic influences. For $\mathrm{E}$, there was no significant evidence for heterogeneity of parameters as a function of sex, and the simplest model consistent with the data was Model 9. For $\mathrm{N}$, both Model 11 , which allowed for additive plus nonadditive genetic effects with a Genotype $\times$ Sex interaction, and Model 4, which allowed for only sex-dependent additive genetic effects with $r_{G}$ estimated as a free parameter, gave equally good fits to the data; neither could be rejected. by likelihood-ratio chi-square test, compared with the most general model. For both $L$ and $P$, although our inspection of the twin correlations suggested the possibility of shared environmental influences, these proved to be nonsignificant. For L, Model 3, allowing for sex-dependent additive generic and within-family environmental effects, was the simplest model consistent with the data. For $P$, although there was an overall sex difference in variability, there was no significant Genotype $\times$ Sex interaction; that is, Model 2 was consistent with the data.

Table 4 summarizes parameter estimates under the best-fitting univariate genetic models. For the TPQ personality vari-

Table 2

Twin Pair Correlations for TPQ and EPQ-R Scales

\begin{tabular}{|c|c|c|c|c|c|c|c|c|c|c|}
\hline \multirow[b]{2}{*}{ Scale } & \multicolumn{2}{|c|}{$\mathrm{MZ}$ females } & \multicolumn{2}{|c|}{ DZ females } & \multicolumn{2}{|c|}{$\mathrm{MZ}$ males } & \multicolumn{2}{|c|}{$D Z$ males } & \multicolumn{2}{|c|}{$\begin{array}{l}\mathrm{DZ} \text { opposite } \\
\text { sex }\end{array}$} \\
\hline & $n$ & $r$ & $n$ & $r$ & $n$ & $r$ & $n$ & $r$ & $n$ & $r$ \\
\hline \multicolumn{11}{|l|}{ IPQ } \\
\hline Harm A voidance & 937 & .44 & 535 & .20 & 399 & .42 & 222 & -.03 & 567 & .09 \\
\hline Noveity Seeking & 933 & .42 & 532 & .14 & 396 & .35 & 222 & .06 & 564 & .07 \\
\hline $\begin{array}{l}\text { Reward Dependence } \\
\text { EPO-R }\end{array}$ & 932 & .38 & 532 & .11 & 396 & .39 & 223 & .18 & 565 & .06 \\
\hline $\begin{array}{l}\text { ExQ-K } \\
\text { Extraversion }\end{array}$ & 941 & .48 & 537 & .20 & 400 & .50 & 221 & .19 & 567 & .16 \\
\hline Neuroticism & 942 & .45 & 538 & .22 & \pm 01 & .34 & 223 & .04 & 569 & .10 \\
\hline Social Conformity & 941 & .43 & 536 & .28 & 200 & .27 & 223 & .20 & 568 & .16 \\
\hline Toughmindedness & 945 & .34 & 538 & $.2 !$ & $\$ 01$ & .36 & 223 & .19 & 569 & .14 \\
\hline
\end{tabular}

Vote. $\mathrm{TPQ}=$ Tridimensional Personality Questionnaire: $E P Q-R=$ revised Eyseack Personality Questionnaire: $M Z=$ monozygotic: $D Z=$ dizygotic. 
Table 3

Results of Univariate Alodel-Filling Analy'ses: Chi-square Tests of Goodness of Fit

\begin{tabular}{|c|c|c|c|c|c|c|c|c|c|c|c|c|c|c|c|c|}
\hline \multirow[b]{3}{*}{ Model } & \multicolumn{7}{|c|}{ Tridimensional Personality Questionnaire } & \multicolumn{9}{|c|}{ Revised Eysenck Personality Questionnaire } \\
\hline & \multirow[b]{2}{*}{$d !$} & \multicolumn{2}{|c|}{ Ilarm Avoidance } & \multicolumn{2}{|c|}{ Novelty Seeking } & \multicolumn{2}{|c|}{$\begin{array}{c}\text { Reward } \\
\text { Dependence }\end{array}$} & \multirow[b]{2}{*}{$d f$} & \multicolumn{2}{|c|}{ Extraversion } & \multicolumn{2}{|c|}{ Neuroticism } & \multicolumn{2}{|c|}{$\begin{array}{l}\text { Social } \\
\text { Conformity }\end{array}$} & \multicolumn{2}{|c|}{$\begin{array}{l}\text { Tough- } \\
\text { mindedness }\end{array}$} \\
\hline & & $x^{2}$ & $p$ & $x^{2}$ & $p$ & $x^{2}$ & $\boldsymbol{p}$ & & $x^{2}$ & $p$ & $x^{2}$ & $p$ & $x^{2}$ & $p$ & $x^{2}$ & $p$ \\
\hline \multicolumn{17}{|c|}{ Additive generic models } \\
\hline 1. he & 13 & 31.71 & $<.001$ & 34.53 & .01 & 39.43 & $<.001$ & 13 & 10.66 & .63 & 25.29 & .02 & 29.44 & $<.(001$ & 60.59 & $<.001$ \\
\hline 2. hek & 12 & 27.32 & $<.01$ & 24.61 & .01 & 22.15 & .03 & 12 & 9.97 & .61 & 24.75 & $<.01$ & 19.05 & .08 & 19.15 & .08 \\
\hline 3. $l i h^{\prime} \mathrm{e} \mathrm{e}^{\prime}$ & 11 & 25.05 & $<.01$ & 21.10 & .03 & 22.11 & .02 & iI & 9.75 & .55 & 15.36 & .16 & 5.05 & .92 & 19.00 & .06 \\
\hline 4. $\| l^{\prime} \mathrm{ee}^{\prime} \mathrm{r}_{\mathrm{G}}$ & 10 & 16.82 & .07 & 14.30 & .20 & 13.37 & .20 & 10 & 4.63 & .91 & 10.30 & .41 & 4.91 & .89 & 17.77 & .05 \\
\hline \multicolumn{17}{|c|}{ Linviromincental models } \\
\hline 5. ce & 13 & 107.73 & $<.001$ & 100.14 & $<.001$ & 94.68 & $<.001$ & 13 & 98.56 & $<.001$ & 88.64 & $<.001$ & 52.84 & $<.001$ & 90.97 & $<.(001$ \\
\hline 6. cek & 12 & 104.33 & $<.001$ & 89.82 & $<.001$ & 76.43 & $<.001$ & 12 & 97.24 & $<.001$ & 88.19 & $<.001$ & 42.67 & $<.001$ & 46.87 & $<.001$ \\
\hline 7. $\mathrm{cc}^{\prime} \mathrm{e} \mathrm{c}^{\prime}$ & 11 & 89.47 & $<.001$ & 79.06 & $<.001$ & 76.14 & $<.001$ & 11 & 95.98 & $<.001$ & 67.53 & $<.001$ & 24.86 & .01 & 46.76 & $<.001$ \\
\hline 8. $c c^{\prime} e e^{\prime} r_{c}$ & 10 & 69.24 & $<.001$ & 61.93 & $<.001$ & 50.40 & $<.001$ & 10 & 66.69 & $<.001$ & 51.62 & $<.001$ & 15.83 & .10 & 33.01 & $<.0(0)$ \\
\hline \multicolumn{17}{|c|}{$\begin{array}{l}\text { Additive plus nonadditive } \\
\text { genelic models }\end{array}$} \\
\hline 9. $h d e^{\circ}$ & 12 & 17.34 & .13 & 18.99 & .08 & 29.08 & $<.001$ & 12 & 3.95 & .98 & 18.17 & .11 & 28.75 & $<.001$ & 60.59 & $<.001$ \\
\hline 10. hdek" & 11 & 11.87 & .37 & 9.75 & .59 & 12.15 & .35 & 11 & 3.41 & .98 & 17.46 & .09 & 18.29 & .07 & 19.15 & .05 \\
\hline II. $h h^{\prime} d d^{\prime} e e^{\prime \prime}$ & 9 & 7.43 & .59 & 7.27 & .60 & 10.05 & .34 & 9 & 2.33 & .98 & 7.03 & .63 & 2.93 & .96 & 17.45 & .04 \\
\hline 12. $h l^{\prime} d d^{\prime} e e^{\prime} r_{0}{ }^{A}$ & 8 & 7.31 & .50 & 7.25 & .51 & 9.93 & .27 & 8 & 2.15 & .97 & 6.83 & .55 & 1.85 & .98 & 17.45 & .02 \\
\hline
\end{tabular}

Nonc. Models 1, 5, and 9 assume no sex differences in genetic and envirommental parameters; Models 2, 6, and 10 allow for an overall sex difference in variance; Models 3,7 , and 11 allow fon the relative magnitudes of genetic and envirommental parameters to differ between men and women; and Models 4,8 , and 12 allow for some sex-specific genetic effects ( $r_{0}<0$. 5 in opposite-sex

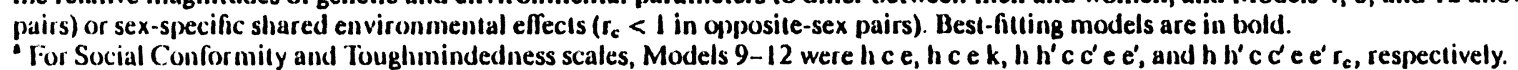


Table 4

Estimates of Standardi=ed Genetic and Environmental Variance Components Under Best-Fitting Univariate Genetic. Kodeis

\begin{tabular}{|c|c|c|c|c|c|c|c|c|c|c|}
\hline \multirow[b]{2}{*}{ Scale } & \multicolumn{4}{|c|}{ Women } & \multicolumn{4}{|c|}{ Men } & & \\
\hline & $\begin{array}{l}\text { Additive } \\
\text { generic }\end{array}$ & $\begin{array}{c}\text { Vonadditive } \\
\text { genetic }\end{array}$ & $\begin{array}{c}\text { Shared } \\
\text { environment }\end{array}$ & $\begin{array}{l}\text { Nonshared } \\
\text { environment }\end{array}$ & $\begin{array}{l}\text { Additive } \\
\text { genetic }\end{array}$ & $\begin{array}{l}\text { Nonadditive } \\
\text { genetic }\end{array}$ & $\begin{array}{l}\text { Shared } \\
\text { environment }\end{array}$ & $\begin{array}{l}\text { Nonshared } \\
\text { environment }\end{array}$ & $r_{G}$ & $k$ \\
\hline
\end{tabular}

TPQ

\begin{tabular}{|c|c|c|c|c|c|c|c|c|c|c|c|}
\hline Harm A voidance & & & & & & & & & & & \\
\hline Model II & 31 & 13 & 0 & 56 & 0 & 42 & 0 & & 58 & 1.00 & $\overline{.95}$ \\
\hline Model 10 & 0 & 44 & 0 & 56 & 0 & 44 & 0 & & 56 & 1.00 & .95 \\
\hline Novelty Seeking & 0 & 41 & 0 & 59 & 0 & 41 & 0 & & 59 & 1.00 & 1.06 \\
\hline $\begin{array}{l}\text { Reward Dependence } \\
\text { Model } 10\end{array}$ & 37 & 0 & 0 & 62 & 39 & 0 & 0 & & 61 & .34 & \\
\hline Model 4 & 2 & 36 & 0 & 63 & 2 & 36 & 0 & & 62 & 1.00 & 1.09 \\
\hline & & & & $E P$ & & & & & & & \\
\hline $\begin{array}{l}\text { Extraversion } \\
\text { Neuroticism }\end{array}$ & 21 & 28 & 0 & 51 & 21 & 28 & 0 & - & 51 & 1.00 & \\
\hline Model 11 & 38 & 7 & 0 & 55 & 3 & 32 & 0 & $\cdots$ & 65 & 1.00 & \\
\hline Model 4 & 45 & 0 & 0 & 55 & 32 & 0 & 0 & & 68 & .5 & \\
\hline Social Conformity & 44 & 0 & 0 & 56 & 27 & 0 & 0 & & 73 & 1.00 & - \\
\hline Toughmindedness & 35 & 0 & 0 & 65 & 35 & 0 & 0 & & 65 & 1.00 & \\
\hline
\end{tabular}

.Vote. Data are reported in percentages. $T P Q=$ Tridimensional Personality Questionnaire; $E P Q-R=$ revised Eysenck Personality Questionnaire.

ables, estimates of broad heritability (i.e., additive plus nonadditive genetic variances), not corrected for measurement error, ranged from $37 \%-44 \%$, with the remaining variance explained by nonshared (i.e., within-family) environmental factors, including measurement error. For NS, and for HA under Model 10 , our estimate of the additive genetic variance went to zero, which is biologically implausible. This probably reflects the problem that in human data, estimates of additive and nonadditive genetic variances are highly negatively correlated (Martin et al.. 1978) so that whereas we can obtain relatively precise estimates of broad heritability, separate estimates of additive and nonadditive genetic effects are very imprecise. Under Model 11 , most of the genetic variance in HA scores in women was additive, but most of the genetic variance in men was nonadditive. For $R D$, whereas estimates of broad heritability were very consistent under Modeis 4 and $10(37 \%-39 \%$ and $38 \%$, respectively), under Model 4, allowing for a Genotype $\times$ Sex interaction with $r_{G}$ estimated as 0.34 , all genetic variance was additive, whereas under Model 10, allowing only for a sex difference in variance, almost all generic variance was nonadditive.

For $E$, we obtained substantial positive estimates of additive and nonadditive genetic variances ( $21 \%$ and $28 \%$, respectively), with a broad heritability of $49 \%$. For $N$, under Model 11 , most of the genetic variance in women was additive, and most of the genetic variance in men nonadditive, a result that closely paralleis findings for HA under the same model. The broad heritability for $N$ was substantially lower in men $(35 \%)$ than in women (45\%). For $P$, genetic factors had a modest effect, accounting for $35 \%$ of the variance, with the remaining variance attributable to within-family environmental effects. Finally, for L, genetic factors were again accountable for a very modest $27 \%$ of the variance for men. and $44 \%$ of the variance for women. with the remaining variance again accounted for by nonshared environmental factors.

\section{Multivariate Genetic Analysis}

Phenotypic within-person correlations between the TPQ and EPQ-R scales were strikingly consistent across sexes. There was a strong positive correlation of $\mathrm{HA}$ with $\mathrm{N}(n=3,819, r=.63$ for women; $n=2,013, r=.63$ for men) and a strong negative correlation with $E$ ( $r s=-.56$ and -.55 , respectively) as well as a weak negative correlation with $\mathrm{P}$ for women $(r s=-.20$ and $-.14)$. Both NS and RD scores were positively correlated with $E$ ( $r s=.41$ and .39 for women; $r s=.42$ and .40 for men). NS was also positively correlated with $\mathrm{P}(r \mathrm{~s}=.24$ and .30$)$ and negatively correlated with $L(r s=-.28$ and -.27$)$. $R D$ scores showed a modest negative correlation with $\mathrm{P}(r=-.15$ for women and -.18 for men). Other correlations were more modest.

We consider first the results of fitting genetic triangular decomposition models predicting the TPQ scales from genetic and environmental factors of the EPQ-R. The full model gave an excellent fit to the data, $x^{2}(357)=343.67, p=.68$. A more parsimonious model (Model 2), which constrained loadings on nonadditive genetic Factors 1 and 2 to be a multiple of the loadings for the corresponding additive genetic factors and which deleted nonadditive genetic Factors 3 and 4, also gave an excellent fit, $x^{2}(397)=379.96, p=.72$, and a fit that was not significantly worse than that of the most general model. $x^{2}(40)=$ $36.29, p=.64$. No significant improvement in fit compared with Model 2, was obtained either by including in the model nonadditive genetic loadings that were multiples of Additive Generic Factors 3 and $4, x^{2}(4)=1.62, p=.31$, or by replacing Nonadditive Genetic Factors 3 and 4 by shared environmental factors, $\chi^{2}(18)=18.51, p=.42$. A further 20 nonsignificant parameters were deleted from Model $2, \chi^{2}(417)=405.44, p$ $=.65$. vielding the genetic triangular decomposition solution summarized in Table 5 . 
The patterns of loadings in Table 5 were remarkabiy consistent for Genetic and Environmental Factors $1-4$ and quite consistent with what would have been predicted from the observed phenotypic correlations. The first within-family environmental factor, an $E$ factor, also had negative loadings on $H A$ and positive loadings on NS and RD; a similar pattern held for the first genetic factor. The second within-family environmental factor, and the second genetic factor, were $N$ factors, with a substantial loading in each case of only one other variable, HA. The pattern of within-family environmental loadings was very similar for men and women, but the ratio of additive genetic to nonadditive genetic loadings for the first two factors was much lower for men $(0.35,0.36)$ than for women $(1.26,2.62)$, impiying that a higher proportion of the genetic variance is nonadditive in origin for men than for women. The third within-family environmental factor for men and the third additive genetic factors for both sexes had a modest negative loading on NS as well as a substantial positive loading on $L$. For the fourth genetic factor, a $P$ factor, there was a substantial negative loading of $R D$ for men as well as a positive loading on NS and a negative loading on HA. Off-diagonal loadings for the fourth genetic factor for women and for the fourth within-family environmental factors for both sexes followed a similar pattern but were reduced in magnitude.
Finally: we note that subsiantial residual genetic loadings were observed for NS and RD. but loadings on HA were more modest.

In the analysis predicting scales of the EPQ-R from genetic and environmental factors of the TPQ, a full seven-factor triangular decomposition model again gave an excellent fit to the data. $\chi^{2}(357)=347.94, p=.62$, and a more parsimonious model. which constrained nonadditive genetic loadings on Factors $1-3$ to be multiples of the corresponding additive genetic loadings (Model 2), aiso gave an excellent fit, $\chi^{2}(387)=382.31$, $p=.56$. and did not lead to a significant deterioration in fit compared with the more general model, $x^{2}(30)=34.37, p=$ .27. An additional 24 nonsignificant parameters were deleted to yieid a simplified triangular decomposition solution, Table 6: $\chi^{2}(411)=405.64, p=.57$. The first within-family environmental factor. a HA factor, also had substantial negative loadings on $E$ and positive loadings on $N$. Loadings on the first genetic factor followed a similar pattern, but with a much higher ratio of nonadditive genetic loadings to additive_genetic loadings for men (6.5) than for women (0.66). The second within-family environmental factor. a NS factor had only modest loadings on E for both sexes and a negative loading on $L$ for men. For the second genetic factor, a NS factor with positive loadings on $E, N$, and $P$

Table 5

Genetic and Environmental Loadings Under a Triangular Decomposition Model Predicting Scales of the TPQ From Scales of the EPQ-R

\begin{tabular}{|c|c|c|c|c|c|c|c|c|c|c|c|c|c|c|}
\hline \multirow[b]{2}{*}{ Scale } & \multicolumn{7}{|c|}{ Women } & \multicolumn{7}{|c|}{ Men } \\
\hline & 1 & 2 & 3 & 4 & 5 & 6 & 7 & 1 & 2 & 3 & 4 & 5 & 6 & 7 \\
\hline
\end{tabular}

Within-family environmental factors

\begin{tabular}{|c|c|c|c|c|c|c|c|c|c|c|c|c|c|c|}
\hline 1. $E$ & .72 & & & & & & & .69 & & & & & & \\
\hline 2. $\mathrm{N}$ & -.16 & .72 & & & & & & -.17 & .79 & & & & & \\
\hline 3. L & -.03 & -.06 & .74 & & & & & -.06 & -.18 & .82 & & & & \\
\hline 4. $P$ & .09 & -.06 & -.08 & .79 & & & & .03 & -.07 & -.04 & .79 & & & \\
\hline 5. $\mathrm{HA}$ & -.37 & .32 & -.04 & -.05 & .56 & & & -.37 & .36 & -.00 & -.05 & .56 & & \\
\hline 6. NS & .22 & .04 & -.09 & .09 & -.04 & .72 & & .28 & -.01 & -.17 & .16 & - & .71 & \\
\hline 7. RD & .23 & .05 & .05 & -.15 & - & - & .74 & .26 & .01 & .07 & -.05 & - & - & .72 \\
\hline
\end{tabular}

Additive genetic factors

\begin{tabular}{|c|c|c|c|c|c|c|c|c|c|c|c|c|c|c|}
\hline 1. E & .54 & & & & & & & .24 & & & & & & \\
\hline 2. $\mathrm{N}$ & -.10 & .62 & & & & & & -.05 & .19 & & & & & \\
\hline 3. L & -.03 & -.14 & .65 & & & & & .01 & .00 & .53 & & & & \\
\hline 4. $P$ & .05 & -.05 & -.08 & .58 & & & & .02 & .01 & -.19 & .57 & & & \\
\hline 5. HA & -.33 & .41 & .03 & -.09 & .26 & & & -.14 & .13 & -.05 & -.15 & -.05 & & \\
\hline 6. NS & .29 & .08 & -.26 & .16 & - & .06 & & .10 & .04 & -.22 & .17 & - & .18 & \\
\hline 7. RD & .27 & .13 & -.02 & -.11 & - & - & .25 & .11 & .06 & .03 & -.26 & - & - & -.06 \\
\hline
\end{tabular}

Nonadditive genetic factors

$\begin{array}{lr}\text { 1. } E & .43 \\ \text { 2. } N & -.08 \\ \text { 3. } L & -.02 \\ \text { 4. } P & .04 \\ \text { 5. HA } & -.26 \\ \text { 6. NS } & .23 \\ \text { 7. RD } & .21\end{array}$

\begin{tabular}{|c|c|c|c|c|c|}
\hline .24 & & & & & \\
\hline-.05 & - & & & & \\
\hline-.02 & - & - & & & \\
\hline .16 & - & - & - & & \\
\hline .03 & - & - & - & .42 & \\
\hline .05 & - & - & - & - & .41 \\
\hline
\end{tabular}

.68
-.14
.03
.05
-.38
.29
.30

.54
.00
.03
.36
.12
.17

$\begin{array}{rr}- & -28 \\ - & .14\end{array}$ 36 .36

Note. Nonadditive genetic loadings constrained to be a multiple of additive genetic loadings for Factors 1 and $2:$ - incicates parameter was deleted from the mode!. $T P Q=$ Tridimensional Personality Questionnaire: $E P Q-R=$ Revised Eysenck Personality Questionnaire. $E=$ Extraversion: $N=$

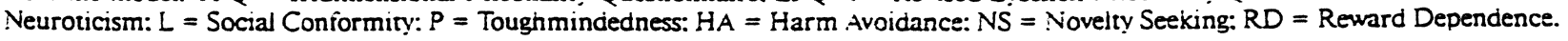


Table 6

Genetic and Environmental Loadings Under a Trianguiar Decomposition :Yodel Predicting Scales of the TPQ From Scales of the EPQ-R

\begin{tabular}{|c|c|c|c|c|c|c|c|c|c|c|c|c|c|}
\hline \multirow[b]{2}{*}{ Scale } & \multicolumn{7}{|c|}{ Women } & \multicolumn{6}{|c|}{ Men } \\
\hline & 1 & 2 & 3 & 4 & 5 & 6 & 7 & 1 & 2 & 3 & 4 & 5 & 6 \\
\hline
\end{tabular}

Within-family environmental factors

\begin{tabular}{|c|c|c|c|c|c|c|c|c|c|c|c|c|c|c|}
\hline $\begin{array}{l}\text { 1. Harm Avoidance } \\
\text { 2. Noveity Seeking } \\
\text { 3. Reward Dependence } \\
\text { 4. Exuraversion } \\
\text { 5. Neuroticism } \\
\text { 6. Social Conformity } \\
\text { 7. Toughmindedness }\end{array}$ & $\begin{array}{r}.75 \\
-.12 \\
-.10 \\
-.36 \\
.39 \\
-.05 \\
-.11\end{array}$ & $\begin{array}{r}.76 \\
.07 \\
.15 \\
.06 \\
-.11 \\
.10\end{array}$ & $\begin{array}{r}.78 \\
.17 \\
.03 \\
.02 \\
-.13\end{array}$ & $\begin{array}{c}.58 \\
-.03 \\
.05\end{array}$ & $\frac{.62}{-}$ & $\begin{array}{r}.73 \\
-.06\end{array}$ & .78 & $\begin{array}{r}.76 \\
-.15 \\
-.14 \\
-.33 \\
.46 \\
-.08 \\
-.08\end{array}$ & $\begin{array}{r}.78 \\
.10 \\
.19 \\
-.00 \\
-.19 \\
.14\end{array}$ & $\begin{array}{r}.76 \\
.14 \\
.03 \\
.08 \\
-.10\end{array}$ & $\begin{array}{r}.56 \\
-.06 \\
-.06\end{array}$ & $\begin{array}{r}.67 \\
-.14 \\
-\end{array}$ & .80 & .75 \\
\hline
\end{tabular}

Additive genetic factors

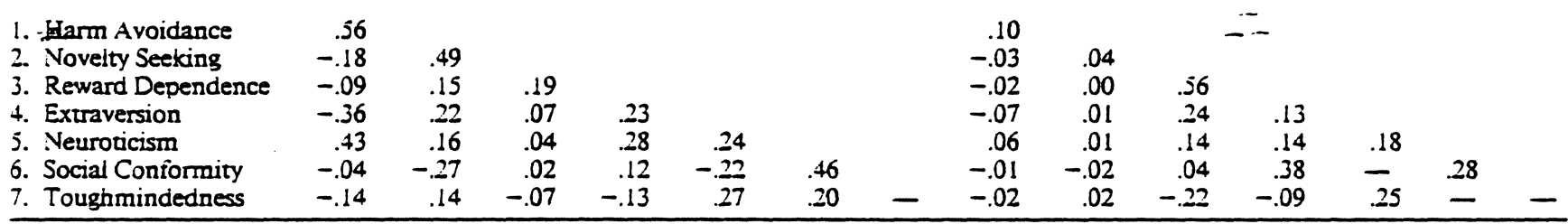

Nonadditive generic/shared environmental factors

\begin{tabular}{|c|c|c|c|c|c|c|c|c|c|c|c|c|c|c|}
\hline 1. Harm Avoidance & .37 & & & & & & & .64 & & & & & & \\
\hline 2. Noveity Seeking & -.12 & .36 & & & & & & -.21 & .56 & & & & & \\
\hline 3. Reward Dependence & -.06 & .11 & .54 & & & & & -.13 & .07 & .26 & & & & \\
\hline 4. Extraversion & -.24 & .16 & .20 & .35 & & & & -.45 & .21 & .11 & .43 & & & \\
\hline 5. Neuroticism & .28 & .12 & .13 & - & - & & & .42 & 22 & .07 & - & .19 & & \\
\hline 6. Social Conformity & -.03 & -.20 & .04 & - & 一 & .24 & & -.04 & -.25 & .02 & - & - & - & \\
\hline 7. Toughmindedness & -.09 & .10 & -.21 & - & 一 & - & $.33_{e}$ & -.15 & .28 & -.11 & - & - & - & $.40_{\mathrm{e}}$ \\
\hline
\end{tabular}

: Vote. Nonadditive generic loadings constrained to be a multiple of additive genetic loadings for Factors 1-j; - indicates parameter was deleted from the model. TPQ = Tridimensional Personality Questionnaire, EPQ-R = revised Eysenck Personality Questionnaire. Subscript $c$ denotes shared environmental loading.

and a negative loading on $\mathrm{L}$, the genetic variance for men was almost entirely nonadditive, whereas for women the ratio of additive to nonadditive genetic loadings was 1.34:1.00. For the third, RD genetic factor, which had a sizable positive loading on $E$ and a negative loading on $P$, the ratio of nonadditive genetic to additive genetic loadings was higher for women (2.9:1) than for men $(0.47: 1)$. The corresponding within-family environmental factor had only a modest loading on $E$ for women $(0.17)$, with all other loadings less than 0.15 in absolute magnitude. Significant loadings of the EPQ scales on Additive and Nonadditive Genetic Factors 47 were observed. implying that not all of the genetic variability assessed by these scales can be accounted for by genetic factors assessed by the TPQ. However. zero estimates were obtained for both sexes for the loading of $P$ on Factor 7 , implying that after controlling for the TPQ factors and residual genetic factors influencing $E . N$, and $L$. all of the genetic variation in $\mathrm{P}$ was accounted for.

Table 7 summarizes the overall estimates of genetic and environmental variances for the TPQ scales (in analyses predicting these scales from the EPQ-R scales) and for the EPQ-R scales (in analyses predicting these scales from the TPQ scales) and subdivides these totals into the variance explained by genetic and environmental factors of the EPQ-R (or TPQ), error vari- ance, and the residual nonerror variance. Thus, from the first column in Table 7, we find that in the analysis predicting the TPQ scales. genetic factors accounted for $44 \%$ of the variance in HA scores for women and nonshared environmental effects for the remaining $56 \%$. Approximately $38 \%$ of the total variance is explained by genetic factors that aiso influence scores on scales of the EPQ-R, 7\% by other ("residual") genetic factors (these totais do not sum to $44 \%$ because of rounding), approximately $25 \%$ by environmental factors that aiso influence EPQ$R$ scores, and $31 \%$ by residual environmental factors (including measurement error, which accounted for 22\% of the total variance). Estimates of broad heritability derived from Table 7 differ somewhat from those reported in Table 5 both because of the use of listwise deletion in the multivariate genetic anaiysis and also because of the additional power for resolving genetic and nongenetic estimates in the multivariate genetic anzlysis. which has led to significant shared environmental loadings being obtained for $\mathrm{P}$ and. for women only, for $\mathrm{L}$. in the analysis predicting scales of the EPQ-R.

For the analysis predicting the TPQ scaies. estimates of residual genetic and environmental variances for $\mathrm{HA}$ were modest for both sexes (less than $11 \%$ in absoiute terms and less than $20 \%$ of the total genetic or environmental variance in all cases). 
Table 7

Results of Fitting Genetic Triangular Decompositton Modeis: Standardized Estimates (\%) of Genetic and Environmental Variance Components for the TPQ and EPQ-R Scales. and Proportions of Variance Accounted for by Genetic and Environmental Factors of the EPQ-R and TPQ. Respectiveiy.

\begin{tabular}{|c|c|c|c|c|c|c|c|c|c|c|c|c|c|c|c|}
\hline \multicolumn{7}{|c|}{ Predicting TPQ scales from the EPQ-R } & \multicolumn{9}{|c|}{ Predicting EPQ-R scales from the TPQ } \\
\hline \multirow[b]{2}{*}{ Parameter } & \multicolumn{3}{|c|}{ Women } & \multicolumn{3}{|c|}{ Men } & \multirow[b]{2}{*}{ Parameter } & \multicolumn{4}{|c|}{ Women } & \multicolumn{4}{|c|}{ Men } \\
\hline & $\mathrm{HA}$ & NS & $R D$ & $\mathrm{HA}$ & NS & $R D$ & & $E$ & $N$ & $L$ & $P$ & $E$ & $N$ & L & $P$ \\
\hline $\begin{array}{l}\text { Nonshared environmental effects } \\
\text { Total environmental variance } \\
\text { Explained by EPQ Factors } 1-4 \\
\text { Error variance } \\
\text { Residuai variance }\end{array}$ & $\begin{array}{r}56 \\
25 \\
22 \\
9\end{array}$ & $\begin{array}{r}58 \\
7 \\
24 \\
28\end{array}$ & $\begin{array}{r}62 \\
8 \\
32 \\
22\end{array}$ & $\begin{array}{l}58 \\
27 \\
22 \\
10\end{array}$ & $\begin{array}{l}63 \\
14 \\
28 \\
22\end{array}$ & $\begin{array}{r}50 \\
7 \\
33 \\
19\end{array}$ & $\begin{array}{l}\text { Nonshared environmental effects } \\
\text { Total environmental variance } \\
\text { Explained by IPQ Factors } 1-3 \\
\text { Error variance } \\
\text { Residual variance }\end{array}$ & $\begin{array}{l}52 \\
18 \\
17 \\
17\end{array}$ & $\begin{array}{l}54 \\
15 \\
19 \\
20\end{array}$ & $\begin{array}{c}55^{\circ} \\
1 \\
21 \\
32\end{array}$ & $\begin{array}{c}66^{\circ} \\
4 \\
37 \\
25\end{array}$ & $\begin{array}{l}48 \\
17 \\
16 \\
15\end{array}$ & $\begin{array}{l}66 \\
21 \\
22 \\
23\end{array}$ & $\begin{array}{r}71 \\
5 \\
20 \\
47\end{array}$ & $\begin{array}{c}60^{d} \\
3 \\
36 \\
21\end{array}$ \\
\hline $\begin{array}{l}\text { Residual variance as percentage of } \\
\text { total environmental variance } \\
\text { Genetic effects } \\
\text { Total genetic variance } \\
\text { Explained by EPQ Factors } 1-4 \\
\text { Residual variance } \\
\text { Residual variance as percentage of } \\
\text { total genetic variance }\end{array}$ & $\begin{array}{r}17 \\
44 \\
38 \\
7\end{array}$ & $\begin{array}{l}42 \\
24 \\
18\end{array}$ & $\begin{array}{l}36 \\
15 \\
23 \\
62\end{array}$ & $\begin{array}{r}41 \\
34 \\
8\end{array}$ & $\begin{array}{l}37 \\
19 \\
18\end{array}$ & $\begin{array}{l}41 \\
20 \\
21\end{array}$ & $\begin{array}{l}\text { Residual variance as percentage of } \\
\text { total environmental variance } \\
\text { Generic effects } \\
\text { Total genetic variance } \\
\text { Explained by TQP Factors } 1-3 \\
\text { Residual variance } \\
\text { Residual variance as percentage of } \\
\text { total genetic variance }\end{array}$ & $\begin{array}{l}48 \\
31= \\
17\end{array}$ & $\begin{array}{r}46 \\
=33 \\
13\end{array}$ & $\begin{array}{l}39 \\
12 \\
27\end{array}$ & $\begin{array}{l}23 \\
11 \\
13\end{array}$ & $\begin{array}{l}52 \\
32 \\
20\end{array}$ & $\begin{array}{r}34 \\
25 \\
9\end{array}$ & $\begin{array}{r}29 \\
7 \\
22\end{array}$ & $\begin{array}{r}24 \\
16 \\
7\end{array}$ \\
\hline
\end{tabular}

Note. Variance components may not sum to unity because of rounding. TPQ = Tridimensional Personality Questionnaire; EPQ-R = revised Eysenck Personality Questionnaire. $H A=$ Harm Avoidance: $N S=$ Novelty Seeking; $R D=$ Reward Dependence; $E=$ Extraversion; $N=$ Neuroticism; $\mathrm{L}=$ Social Conform; $\mathrm{P}=$ Toughmindedness.

- Estimated from test-retest correlations as $(1-r)$. ' Includes additive and nonadditive genetic variance. Excludes shared environmental variance component (6\% in women oniy). "Excludes shared environmental variance component (11\% in women and $16 \%$ in men).

Estimates of residual genetic and environmental variances for NS and RD were much more substantial (18\%-28\% of the total variance). Environmental factors of the $E P Q$ accounted for only a modest proportion of the total variation in NS and RD (7\%$14 \%$ ), but genetic factors accounted for a somewhat higher percentage $(15 \%-24 \%)$. For the analysis predicting the EPQ-R scales, estimates of the residual genetic variances for $P$ and $N$ were modest for men $(7 \%, 9 \%)$ and quite modest for women ( $13 \%$ for each scale); however. more substantial residual genetic variances were found for both $E$ and $L$. Estimates of residual environmental variance were substantial for all four scales.

\section{Conclusions}

\section{Generali=ability of Results}

The Australian NH\&MRC twin panel is a volunteer sample. and only those twin pairs who had previously responded to a mailed questionnaire survey conducted in 1981 (Eaves et al.. 1989: Martin \& Jardine. 1986) were included in the target sample for the 1989 survey. Thus, there are many stages at which nonrandom sampling might have occurred, which could lead to biased estimates of genetic and environmental influences on personality (Lykken et al., 1987; Neale. Eaves. et al. 1989) and limit the generalizability of our findings. However. the representativeness of the original 1981 sample when compared with EPQ norms for Australia (Martin \& Jardine, 1986), and the absence of mean differences between twins from pairs concordant for participation in the 1989 survey and twins whose cotwin wouid not take part. suggests that any sampling bias with respect to these personality dimensions must be relatively slight and therefore unilikely to bias estimates of genetic and environmental influences.

A more direct test of the generalizability of findings from this sample is available for the Eysenckian personality dimensions of $E$ and $N$. where comparisons of results from the univariate genetic analyses with results from systematically ascertained twin samples can be made. For $E$, the finding of no shared environmental effects. substantial genetic nonadditivity, and additive genetic influences in both sexes, with no Genotype $\times$ Sex interaction. is in agreement with results from surveys of the Virginia Twin Register (Eaves et al.. 1993) and the Finnish Twin Register (Rose et al.. 1988: reanalyzed in Eaves et äl., 1993), two birth certificate derived registers. Less surprisingly, these conclusions are also in agreement with results from the 1981 survey of this same Australian sample (Eaves et al., 1989; Eaves et al., 1993; Martin \& Jardine. 1986). For N, results under Model 11 (allowing for additive plus nonadditive genetic effects. with a Genorype $\times$ Sex interaction) are again in agreement with the American and Finnish samples, and the Australian 1981 survey, in indicating a higher additive genetic variance for women and a higher nonadditive genetic variance for men. Even the relatively low male $\mathrm{MZ}$ correlation for $\mathrm{N}(0.34)$ is strikingly similar to the corresponding correlations observed in the American $(0.35)$ and Finnish $(0.33)$ samples. The evidence for a genetic influence on $E$ and $N$. with no effect of shared family environment. is also supported by separated twin (Pedersen et ai. 1988) and adoption (Scarr et al.. 1981) data. although in these latter data sets sample sizes were too small to permit a resolution of the interaction of additive and nonadditive genetic influences with sex. For Toughmindedness and Social Confor- 
mity, although the twin correlations suggested shared environmental as well as genetic intluences on responding, consistent with findings from previous twin surveys (Eaves et al., 1989), the shared environmental effects were not significant in the univariate genetic analyses.

\section{The Inheritance of the TPQ Personality Dimensions}

Results of fitring univariate generic models to the TPQ personality data confirmed the hypothesized significant genetic influence on each of the personality dimensions of HA, NS, and $R D$. For each personality dimension, nongenetic models were rejected by chi-square test of goodness of fit. Findings for NS were very similar to those for $E$, with substantial genetic nonadditivity in both sexes and no Genotype $\times$ Sex interaction. Findings for $H A$, under Model 11, were strikingly similar to those for $\mathrm{K}$, with much higher additive genetic variance for women and much higher nonadditive genetic variance for men. For $R D$, a simple additive genetic model, allowing for a Genotype $\times$ Sex interaction, including sex-dependent genetic effects (with a correlation between genetic effects in the two sexes of only 0.34 ), gave a good fit to the data.

From the 2-year test-retest correlations, we can estimate that as much as $22 \%$ of the variance in HA scores, $24 \%$ (for women) to $28 \%$ (for men) of the variance in NS scores, and $32 \%-33 \%$ of the variance in $R D$ scores is attributable to measurement error and other relatively short-term state effects. Thus, if unreliability of measurement is entirely environmental in origin (as would be the case if it is solely determined by measurement error), approximately $54 \%-56 \%$ of the stable variation in HA for men and women, and $58 \%-61 \%$ of the stable variation in NS, is determined by additive and nonadditive genetic influences, and approximately $54 \%-58 \%$ of the stable variation in $R D$ is determined by genetic influences that are purely additive, with the remaining variation in each trait determined by within-family environmental effects, that is, by the stable influences of within-pair differences in environmental experience (Plomin \& Daniels, 1987). In comparison, additive and nonadditive genetic factors accounted for approximately $60 \%$ of the stable variation in $E$ for men and $59 \%$ for women and between $41 \%$ and $48 \%$ of the stable variation in $N$ for men but $56 \%$ for women. The reduced impact of genetic factors on $\mathrm{N}$ for men, although consistent with the Finnish and American studies (Eaves et al., 1989; Rose et al., 1988), is not consistent with findings using previous versions of the $E P Q$, inciuding the 1981 survey of this same sample (Eaves et al., 1989), and we suspect may reflect largely differences between short-form measures of $\mathrm{N}$ and the full 23-item scale used in the 1981 survey. Additive genetic factors accounted for approximately $34 \%$ of the stable variance in L scores for men but $56 \%$ for women and for $56 \%$ of the stable variance in $P$ for women and $54 \%$ for men. However it should be noted that because of the 2-year test-retest interval. we cannot exclude the possibility that inconsistency of subjects' responses across occasions is in part genetically determined and not solely the consequence of measurement error, in which case these estimates of the proportion of stable variation accounted for by genetic factors may be overestimates (Eaves \& Eysenck. 1976: Eaves et ai.. 1989).

\section{Underlying Genetic Structure}

By fitting a multivariate genetic trianguiar decomposition model (Neaie \& Cardon. 1992), we explored the extent to which the TPQ and EPQ-R assess the same versus different dimensions of genetic and environmental variability. From the environmental perspective, it appears that the TPQ NS and RD dimensions, in particular, are substantially influenced by environmental factors whose influence is specific to the TPQ as well as by factors that aiso influence responding to the EPQ-R. For $H A$, in contrast, most of the residual environmental variance that was not explained by environmental factors of the EPQ (i.e., by environmental factors that also influence responding to EPQ scales) could be explained as error variance. In analyses predicting the scales of the EPQ- $R$ from the TPQ, $L$ and $P$ scales assess environmental variability that is not assessed by the TPQ. For $E$ and $N$, although sizable proportions of the nonerror environmental variance can be explained-by environmental factors of the TPQ (43\%-53\%), substantial residual environmental variability remains. Thus, from an environmental perspective, it appears that the seven higher order scales of the TPQ and EPQ$R$ assess six dimensions of variability, with the HA scale adding little to the assessments provided by the $E$ and $N$ scales.

From a genetic perspective there was also a substantial overlap between the dimensions of genetic variation assessed by the TPQ HA and EPQ-R E and N scales. In the analysis predicting scales of the TPQ, less than 10\% of the total variance in $\mathrm{HA}$ scores was residual genetic variance that was not accounted for by the genetic factors of the EPQ-R. However, the higher broad heritability of HA, compared with $\mathrm{N}$, for men leads us to suspect that the short-form TPQ provides a better assessment of this heritable variation than the short-form EPQ- $R$. For the $T P Q$, substantial residual genetic variance was observed both for $R D$ and for NS. For the EPQ-R, although substantial residual genetic variance was found for both $E$ and $L$, residual variance for the $\mathrm{N}$ and $\mathrm{P}$ scales was much more modest. particularly for men. This suggests that the TPQ personality dimensions of $H A$. NS, and $R D$, together with $E$ and $L$, may provide a more parsimonious, five-dimensional description of the genetic structure of personality than the six-dimensional description provided by the EPQ-R dimensions plus NS and $R D$.

Factor loadings obtained under the multivariate genetic triangular decomposition models allow us to consider the underiying genetic and environmental structures of personality from the alternative frameworks provided by the theories of Eysenck (Eysenck \& Eysenck, 1985) and those of Cloninger (1986, 1987, 1988), Gray (1982), and others. In the Eysenckian tramework (Table 5 ), we found orthogonal environmental factors determining $E$ (associated with a modest decrease in $\mathrm{HA}$ and increases in RD and NS), $N$ (and HA), L (with decreased NS for men), and $P$ (with increased NS for men and decreased $R D$ for women). In the framework of Cloninger. Gray, and others (Table 6), we obtained orthogonal environmental factors determining $\mathrm{HA}$ (associated with increased $\mathrm{N}$ and decreased $\mathrm{E}$, consistent with Gray's Anxiety construct). NS (with a slight increase in $E$ and a decrease in $L$ for men), and $R D$ (with a slight increase in E). In the Eysenckian framework. we found orthogonal genetic factors determining $E$ (and associated with decreased $H A$ scores and increased NS and increased RD), $N$ and HA, L (with de- 
creased NS). and P (associated with decreased RD. decreased HA. and increased NS). Substantial genetic nonadditivity was lound for the first two $E$ and $N$ genetic factors but not for the $L$ or $\mathrm{P}$ factors. In the Cloninger-Gray framework, we found orthogonal additive and nonadditive generic HA/Anxiety, NS, and $R D$ factors in both sexes, with the partern of loadings of the EPQ scales on these factors closely paralleling those observed ior the environmental factors of the TPQ.

Perhaps the most striking conclusion from these analyses. however, is that two personality systems that purport to describe the structure of personality in terms of three major dimensions or four if we include the I scale of the EPQ-R as a Social Conormity measure) appear instead to jointly assess five or six dimensions of genetic variability and at least six dimensions of environmental variability. The relatively high proportion of residual genetic variance found for NS may in part be a consequence of changes in the operationalization of $E$ in the $E P Q$, which have led to deletion of impuisivity items from earlier versions of.that scale (see Gray, 1981). The RD construct of the IPQ appears to be conceptually quite different from the Eysenckian personality dimensions. so that the finding of substantial residual genetic and environmental variance for this scale is less surprising. Conversely, whereas the failure of the TPQ to account for genetic variability in Social Conformity, as assessed by the I scale, was anticipated, the substantial residual genetic variance found for $E$ suggests that the TPQ only partially accounts for genetic influences on sociability, the predominant trait assessed by the EPQ E scale. It remains to be seen whether the recent extension of Cloninger's personality system to seven nigher order dimensions of "temperament and character" (Cloninger, Svrakic, \& Przybeck, 1993; Svrakic, Whitehead, Pryzbeck, \& Cloninger, 1993) will change these conclusions.

The simpie triangular decomposition models that we have fitted in this articie have allowed us to determine the extent to which the personality instruments of Eysenck and Cloninger assess the same or different dimensions of underlying genetic variability. However, they provide merely a starting point for addressing the question of whether the personality theories of Cloninger or Eysenck provide a better description of the underlying genetic structure of personality. By fitting multivariate genetic factor models (Heath, Eaves, \& Martin. 1989; Heath, Jardine, \& Martin, 1989; Heath, Neale, et al., 1989; Martin \& Eaves. 1977; Neale \& Cardon, 1992), it may be possible to show that one model provides a more parsimonious description. requiring, for example, fewer dimensions of nonadditive genetic variation than the other. This question. which may be better addressed at the level of the primary rather than higher order factors or by multivariate genetic item anaiysis (Heath. Eaves, \& Martin. 1989; Heath, Jardine, \& Martin. 1989; Heath \& Martin, 1990) will be addressed in the future.

\section{References}

Bouchard. T. J.. Lykken. D. T.. McGue. M.. Segal. N. L.. \& Tellegen. A. (1990). Sources of human psychological differences: The Minnesota Study of Twins Reared Apart. Science. 250. 223-228.

Buimer. M. G. (1980). The mathematicai theory of quantitative genetics. Oxford. England: Clarendon Press.

Cloninger. C. R. (1986). A unineed biosocial theory of personaiity and its role in the development of anxiety states. Psychiatric Deveiopments. j. $167-226$.

Cloninger. C. R. (1987). A systematic method for ciinical description and classincation of personality variants: A proposal. Archives of General Psuchiatry: 44. 573-588.

Cloninger. C. R. (1988). Anxiety and theories of emotions. In R. Noves. M. Roth. \& G. D. Burrows (Eds.). Handbook of anxiety (Vol. 2, pp. 1-29). Amsterdam: Elsevier.

Coninger. C. R. (1991). Brain networks underiying personality development. In B. J. Carroll \& J. E. Barrett (Eds.), Psychopathology and the orain (pp. 183-208). New York: Raven Press.

Cloninger. C. R., Przybeck. T. R., \& Svrakic. D. M. (1991). The Tridimensional Personality Questionnaire: U.S. normative data. Psychological Reports. 69. 1047-1057.

Cioninger, C. R. Svrakic, D. M.. \& Przybeck. T. R. (1993). A psychobiological model of temperament and character. Archives of General Psychiatry, 50, 975-990.

Eaves, L. J. (1977). Inferring the causes of human variation. Journal of the Royal Statistical Society, 140. 324-355.

Eaves. L. J.. \& Eysenck. H. J. (1976). Generic and environmental components of inconsistency and unrepearabilitzk in twins' responses to a neuroticism questionnaire. Behavior Genetics. 6. 145-160.

Eaves. L. J.. \& Eysenck. H. J. (1977). A genotype-environmental model for psychoticism. Advances in Behavior Research and Therapy, 1. 526.

Eaves, L. J., Eysenck. H. J.. \& Martin, N. G. (1989). Genes, culture and personality: An empirical approach. San Diego, CA: Academic Press.

Eaves, L. J., Heath, A. C.. Neale. M. C.. Hewir. J. K. \& Martin, N. G. (1993). Sex differences and non-additivity in the effects of genes on personality. Unpublished manuscript. Virginia Commonwealth University.

Eaves, L. J.. Last, K. A, Mariin, N. G., \& Jinks, J. L. (1977). A progressive approach to non-additivity and genotype-environmental covariance in the analysis of human difierences. British Joumal of Mathematical and Statistical Psychology, 30, 1-42.

Eysenck. H. J., \& Eysenck. S. B. G. (1969). Personality structure and measurement. New York: Routledge, Chapman \& Hall.

Eysenck, H. J.. \& Eysenck. S. B. G. (1975). Manual of the Eysenck Personality Questionnaire. London: Hodder \& Stoughton.

Eysenck. H. J., \& Eysenck, S. B. G. (1976). Psychoticism as a dimension of personality. London: Hodder \& Stoughton.

Eysenck. H. J., \& Eysenck. M. W. (1985). Personalizy and individual differences. New York: Plenum.

Eysenck. H. J.. Eysenck. S. B. G.. \& Barrert. P. (1985). A revised version of the Psychoticism scale. Personality and Individual Differences. 6. $21-29$.

Fisher, $R$ A. (1918). The correlation between relatives on the supposition of Mendelian inheritance. Transactions of the Royal Society of Edinburgh. 52. 399-433.

Gray, J. A. (1981). A critique of Eysenck's theory of personality. In H. J. Eysenck (Ed.), A model for personality (pp. 246-276). New York: Springer-Verlag.

Gray, J. A. (1982). The neuropsychology of anxiety. New York: Oxford University Press.

Heath. A. C.. Eaves, L. J.. \& Martin, N. G. (1989). The genetic structure of personality III. Multivariate genetic item analysis of the EPQ scales. Personalizy and Individual Differences, 10.877-888.

Hearh. A. C.. Jardine. R.. Eaves. L. J.. \& Martin. N. G. (1988). The genetic structure of personality I. Phenotypic factor structure of the $E P Q$ in an Australian sample. Personality and Indiviaual Differences. 9. 59-6i.

Heath. A. C., Jardine. R.. \& Martin. N. G. (1989). The genetic structure of personality II. Genetic item analysis of the EPQ. Personality and Individual Differences. 10. 615-024. 
Heath. A. C., \& Martin. V. G. (1990). Psychoticism as a dimension of personality: A multivariate genetic test of Eysenck and Eysenck's psychoticism construct. Joumal of Personality and Social Psychology. 58. $1-11$.

Heath. A. C., Neale, M. C., Hewith. J. K., Eaves. L. J., \& Fulker D. W. (1989). Testing structural equation modeis for twin data using LISREL. Behavior Genetics. 19. 9-35.

Heath, A. C., Neale, M. C., Kessier, R. C., Eaves. L. J., \& Kendler. K. S. (1993). Evidence for generic influences on personality from self-reports and informant ratings. Journal of Personality and Social Psychology, 63. 85-96.

Jöreskog, K., \& Sörbom. D. (1988). LISREL VII: Analysis of linear structural relationships. Mooresville, IN: Scientific Software.

Kendler, K. S, Heath, A. C., Martin. N. G.. \& Eaves, L. J. (1987). Symptoms of anxiety and symptoms of depression: Same genes, different environments? Archives of General Psychiarry, 122. 451-457.

Loehlin, J. C. (1981). Personality resemblances in adoptive families. Behavior Genetics. 11. 309-330.

Loehlin, J. C. (1992). Genes and environment in personality developmënt: Individual differences and development series (Vol. 2). Newbury Park. CA: Sage.

Loehlin. J. C., Willerman. L., \& Horn, J. (1985). Personality resemblances in adoptive families when the children are late-adolescent or adult. Joumal of Personality and Social Psychology, 48. 376-392.

Lykken. D. T., McGue, M., \& Tellegen. A. (1987). Recruitment bias in twin research: The rule of two-thirds reconsidered. Behovior Generics. 17, 343-362.

Lykken, D. T., Tellegen, A., \& DeRubies. R. (1978). Volunteer bias in twin research: The rule of two-thirds. Social Biology, 25. 1-9.

Martin, N. G., \& Eaves, L. J. (1977). The genetical analysis of covariance structure. Heredity, 28, 79-95.

Marin, N. G., Eaves, L. J., \& Fulker D. W. (1979). The generical relationship of impuisiveness and sensation-seeking to Eysencx's personality dimensions. Acta Geneticae Medicae et Gemellologiae. 28. 197210.

Martin. N. G., Eaves, L. J., Kearsey, M. J., \& Davies, P. (1978). The power of the classical twin study. Heredity, 40. 97-116.

Martin. N. G.. \& Jardine. R. (1986). Eysenck's contribution to behavior generics. In S. Modgil \& C. Modgil (Eds.), Hans Eysenck: Consensus and controversy (pp. 213-218). Sussex. England: Faimer Press.

Martin, N. G., \& Wilson, S. R. (1982). Bias in the estimation of heritability from truncated samples of twins. Behavior Genetics. 12. 467472.

Mather K., \& Jinks. J. L. (1971). Biometrical genetics: The study of continuous variation. London: Chapman \& Hall.

McCrae, R. R. \& Costa. P. T. (1989). The structure of interpersonal traits: Wiggins's circumplex and the five-factor model. Joumal of Personality and Social Psychology, 56. 586-595.

Morrison, D. F. (1976). Multivariate statistical methods. New York: McGraw-Hill.
Veale, M. C.. \& Cardon. L. R. (1992). Methodology for genetic studies of twins and families. VATO ASI Series D: Benavioral and social sciences (Vol. 67). Norwell. MA: Kluwer Academic.

Neale, M. C., Eaves. L. J., Kendler, K. S.. \& Hewitt. J. K. (1989). Bias in correlations from selected samples of relatives: The effects of soft seiection. Behavior Genetics. 19, 163-169.

Neale. M. C., Henth. A. C. Hewitt J. K. Eaves. L. J., \& Fulker. D. W. (1989). Fitring genetic models with LISREL: Hypothesis-iesting. Behavior Genetics. 19. 37-49.

Pedersen. N. L., Plomin, R., McClearn, G. E., \& Friberg, L. (1988). Neuroticism, extraversion. and related traits in aduit twins reared apart and reared together Journal of Personality and Social Psychology, 55. 950-957.

Pedersen. N. L., McClearn, G. E., Plomin, R., Nesselroade, J. R., Berg. S., \& de Faire, U. (1991). The Swedish Adoption/Twin Study of Aging: An update. Acta Geneticae Medicae et Gemellologiae, 40. 720.

Plomin. R., \& Danieis, D. (1987). Why are children in the same family so different from one another? Behavioral Brain Science. 10, 1-60.

Plomin, R., DeFries, J. C., \& Loehlin. J. L. (1977). Genotype-environment interaction and correlation in the analysis of human variation. Psychological Bulletin, 84, 309-322.

Rose, R. J., \& Kaprio, J. (1988). Frequency of social contact and resemblance of aduit monozygotic cotwins-Or does shared experience inGuence personality after all? Behovior Genetics. 18, 309-328.

Rose, R. J., Koskenvuo, M. Kaprio, J., Sarna, S., \& Langinvainio, H. (1988). Shared genes, shared experiences, and similarity of personality: Data from 14,228 Finnish co-twins. Joumal of Personality and Social Psychology, 54, 161-171.

Scarr, S., Webber, P. L., Weinberg, R. A., \& Wittig, M. A. (1981). Personality resemblance among adolescents and their parents in biologically related and adoptive families. Joumal of Personality and Social Psychology, 40, 885-898.

Shields, J. (1962). Monozygotic twins: Brought up apart and brought up together. Oxford: Oxford University Press.

Surakic, D, Whitehead, C., Pryzbeck. T. R. \& Cloninger, C. R. (1993). Differential diagnosis of personality disorders by the seven factor model of temperament and character. Archives of General Psychiatry, 50. $991-999$.

Tellegen. A. (1985). Structure of mood and personality and their relevance to assessing anxiery, with an emphasis on self-report. In $A$. H. Tuma \& J. D. Maser (Eds.), Anxiery and the anxiety disorders (pp. 681-706). Hillsdale, NJ: Eribaum.

Tellegen, A., Lykken, D. T., Bouchard. T. J., Wilcox, K. J., Segail, N., \& Rich, S. (1988). Personality similarity in twins reared apart and together Journal of Personality and Social Psychology, 54, 10311039.

Received March 10, 1992

Revision received October 21, 1993 Accepted October 28, 1993 = 